\title{
A New Gas Chromatography/Mass Spectrometry (GC-MS) Method for the Multiresidue Analysis of Pesticides in Bread
}

\author{
Diana I. Kolberg, Osmar D. Prestes, Martha B. Adaime and Renato Zanella* \\ Departamento de Química, Universidade Federal de Santa Maria, \\ 97105-900 Santa Maria-RS, Brazil
}

\begin{abstract}
Neste trabalho desenvolveu-se um método para a determinação de 15 pesticidas em pão utilizando cromatografia gasosa acoplada à espectrometria de massas (GC-MS), operando no modo de ionização química negativa (NCI). No preparo da amostra utilizou-se acetonitrila contendo $1 \%$ (v/v) de ácido acético, na presença de acetato de sódio, citrato de sódio e sulfato de magnésio. O método foi validado avaliando os seguintes parâmetros: linearidade, limite de detecção (LOD), limite de quantificação (LOQ), precisão e exatidão. A faixa linear utilizada foi de 1,0-100 $\mu \mathrm{g} \mathrm{L}^{-1}$. As recuperações foram consideradas satisfatórias apresentando valores entre 70 e $117 \%$, com $\mathrm{RSD} \leq 17,6 \%$ para quase todos os compostos. O LOQ do método variou de 10 a $20 \mu \mathrm{g} \mathrm{kg}^{-1}$. O método demonstrou ser adequado, sensível e altamente seletivo para a análise multirresíduo de pesticidas em pão.
\end{abstract}

In this work a method for the determination of 15 pesticides in bread samples using gas chromatography coupled with mass spectrometry (GC-MS), operating in the negative chemical ionization mode $(\mathrm{NCI})$ was developed and validated. For the extraction procedure acetonitrile containing $1 \%(\mathrm{v} / \mathrm{v})$ acetic acid was used in presence of sodium acetate, sodium citrate and magnesium sulphate. The method was validated evaluating the following parameters: linearity, limit of detection (LOD), limit of quantification (LOQ), precision and accuracy. The linear range used was from 1.0 to $100 \mu \mathrm{g} \mathrm{L}{ }^{-1}$. The recoveries had been considered satisfactory presenting values between 70 and $117 \%$ with RSD $\leq 17.6 \%$ for almost all the compounds. The real method LOQ ranged from 10 to $20 \mu \mathrm{g} \mathrm{kg}^{-1}$. The method shown to be adequate for the multiresidue analysis of pesticides in bread and the GC-MS (NCI) proved to be sensitive and highly selective.

Keywords: pesticides, multiresidue, bread, GC-MS

\section{Introduction}

Pesticides have played a very important role in the development of the agriculture since their invention, which were still irreplaceable until the present time. Therefore, different countries have promulgated their own residue limits in the international trade. There are many analytical methods for determination of pesticide multiresidues in agricultural products and animal derived foods, but the key technique is: firstly, how several dozens of varieties or even hundreds of pesticide residues can be thoroughly extracted from the complex matrixes; secondly, how a great deal of interfering matters co-extracted with the pesticides can be cleaned up; thirdly, what analytical modes should be adopted for the pesticide determination. ${ }^{1}$

*e-mail: renatozanella@pq.cnpq.br
Wheat is a major cereal grain cultivated throughout the world and one third of this cereal is consumed by milling and baking. ${ }^{2,3}$ Commercially produced bread is an important component of every day diet in many countries. During bread making process, flour is subjected to biological (fermentation) and physical (baking) transformation. ${ }^{3,4}$

The cultivation and storage of grains often require the intensive use of pesticides, which may be present in grains and in foods prepared from them. ${ }^{5}$

In the last years, many researchers have published about pesticide analysis in food matrices. ${ }^{6-13}$ However, in these studies the mainly matrices were fruits and vegetables. Sample preparation is always the major bottleneck in any analytical procedure, in 2003 a method that provided high quality results with a minimum number of steps and a low solvent and glassware consumption, was published. ${ }^{14}$ The 
method was given an acronymic name, QuEChERS, that reflected its major advantages (quick, easy, cheap, effective, rugged, and safe). The QuEChERS procedure omits or replaces many complicated analytical steps commonly employed in traditional methods by easier ones. The original procedure consists of extracting the homogenized sample by hand-shake or Vortex with the same amount of acetonitrile in order to have a final extract concentrated enough without the need of a solvent evaporation step. The technique has attracted the attention of pesticide analysis studies worldwide, ${ }^{15-18}$ and a review has been published recently..$^{19}$ In the other hand, the research about pesticides analysis in dry samples (e.g. cereals) and in processed food still require new developments. ${ }^{20,21}$

The main objective of this work was demonstrating the potential sample preparation of a miniaturized acetonitrilebased extraction followed by a dispersive solid phase extraction (D-SPE) clean-up step. ${ }^{13}$ Unlike traditional methods using SPE tubes, in D-SPE clean-up is facilitated by mixing bulk amounts of sorbent with a aliquot of extract. In addition evaluating the GC coupled with a quadrupole mass analyzer operated in negative chemical ionization (NCI) mode for sensitive and reliable multiresidue method for pesticide analysis in bread samples.

\section{Experimental}

\section{Apparatus}

A Varian CP-3800 gas chromatograph equipped with electronic flow control (EFC), a 1079 PTV injector, a CP 8400 autosampler and a 1200 triple quadrupole mass spectrometer (Varian, Walnut Creek, USA). Analytical balance HR-120 (A \& D, Tokyo, Japan), Ultraturrax blender (Kinematica, Lucerne, Switzerland), bread machine (Britânia, São Paulo, Brazil) and a Jouan C 412 (SaintHerblain, France) centrifuge were employed.

\section{Reagents and materials}

Acetonitrile pesticide residue grade and acetic acid analytical grade were obtained from Merck (Darmstadt, Germany). Toluene and isooctane were both pesticide residue grade (J.T. Baker, Phillipsburg, USA). Anhydrous magnesium sulphate $\left(\mathrm{MgSO}_{4}\right)$, anhydrous sodium acetate, sodium citrate tribasic dehydrate, sodium chloride all reagent grade were purchased from Merck (Rio de Janeiro, Brazil). Water was freshly purified using a Direct UV3 system (Millipore, Molsheim, France). Adsorbent $\mathrm{C}_{18}$ $(55 \mu \mathrm{m})$ was obtained from Phenomenex (Torrance, USA). Polypropylene centrifuge tubes (Sarstedt, Nümbrecht,
Germany), $50 \mathrm{~mL}$ volume for initial extraction, and $15 \mathrm{~mL}$ volume for D-SPE step were used.

Pesticide solid standards of azoxystrobin, chlorthalonil, chlorpyrifos-ethyl, chlorpyrifos-methyl, dicofol, $\alpha$-endosulfan, $\beta$-endosulfan, endosulfan-sulfate, endrin, fenithrothion, lindane, malathion, parathion-ethyl, pirimiphos-methyl and tetradifon (purity $>94.0 \%$ ) were obtained from Dr. Ehrenstorfer (Augsburg, Germany). Stock standard solutions $\left(1,000 \mathrm{mg} \mathrm{L}^{-1}\right)$ of individual pesticides were prepared in toluene. Working standard mixture in toluene, containing $1 \mathrm{mg} \mathrm{L}^{-1}$ of each pesticide, was prepared for use as spiking solution and for the analytical curves.

\section{Bread making}

The bread sample was made in the laboratory with a bread machine using standard procedure: $750 \mathrm{~g}$ of wheat flour was mixed with $10 \mathrm{~g}$ dry yeast, $20 \mathrm{~g}$ vegetable fat, $5 \mathrm{~g}$ salt and $40 \mathrm{~g}$ milk powder. The ingredients were mixed and kept for fermentation inside of bread machine at a temperature of $30^{\circ} \mathrm{C}$ during $15 \mathrm{~min}$, after that the temperature was set at $180^{\circ} \mathrm{C}$ for $45 \mathrm{~min}$.

\section{Sample extraction}

A sub-sample of $500 \mathrm{~g}$ of bread was homogenized in Ultraturrax at high speed with $500 \mathrm{~mL}$ of purified water to give an homogeneous slurry (paste) from which aliquots are taken for analysis.

A $10 \mathrm{~g}$ portion of slurry previously homogenized was weighed in a $50 \mathrm{~mL}$ centrifuge tube. Ten milliliters of acetonitrile, containing $1 \%(\mathrm{v} / \mathrm{v})$ of acetic acid, were then added to the sample, and the mixture was hand-shaken for $1 \mathrm{~min}$. Afterwards $3 \mathrm{~g}$ of anhydrous $\mathrm{MgSO}_{4}$ were added and the tube was hand-shaken immediately for $20 \mathrm{~s}$. Later, $1.7 \mathrm{~g}$ of sodium acetate and $1 \mathrm{~g}$ of sodium citrate were added and the tube was hand-shaken for another $1 \mathrm{~min}$ to provide well-defined phase separation after $8 \mathrm{~min}$ of centrifugation at 4,000 rpm. During the clean-up step, $4 \mathrm{~mL}$ aliquot of the upper layer was transferred to a centrifuge tube $(15 \mathrm{~mL})$ containing $0.6 \mathrm{~g}$ of anhydrous $\mathrm{MgSO}_{4}$ and $0.5 \mathrm{~g}$ of adsorbent $\mathrm{C}_{18}$. The tube was hand-shaken for $1 \mathrm{~min}$ and centrifuged at $4000 \mathrm{rpm}$ for $8 \mathrm{~min}$. An aliquot of the supernatant was transferred into an autosampler vial to its injection into the GC-MS system. Figure 1 shows a scheme of the modified QuEChERS method used in this work.

\section{Equipment parameters}

The chromatographic conditions separation was performed in a capillary fused silica column VF-5 MS 


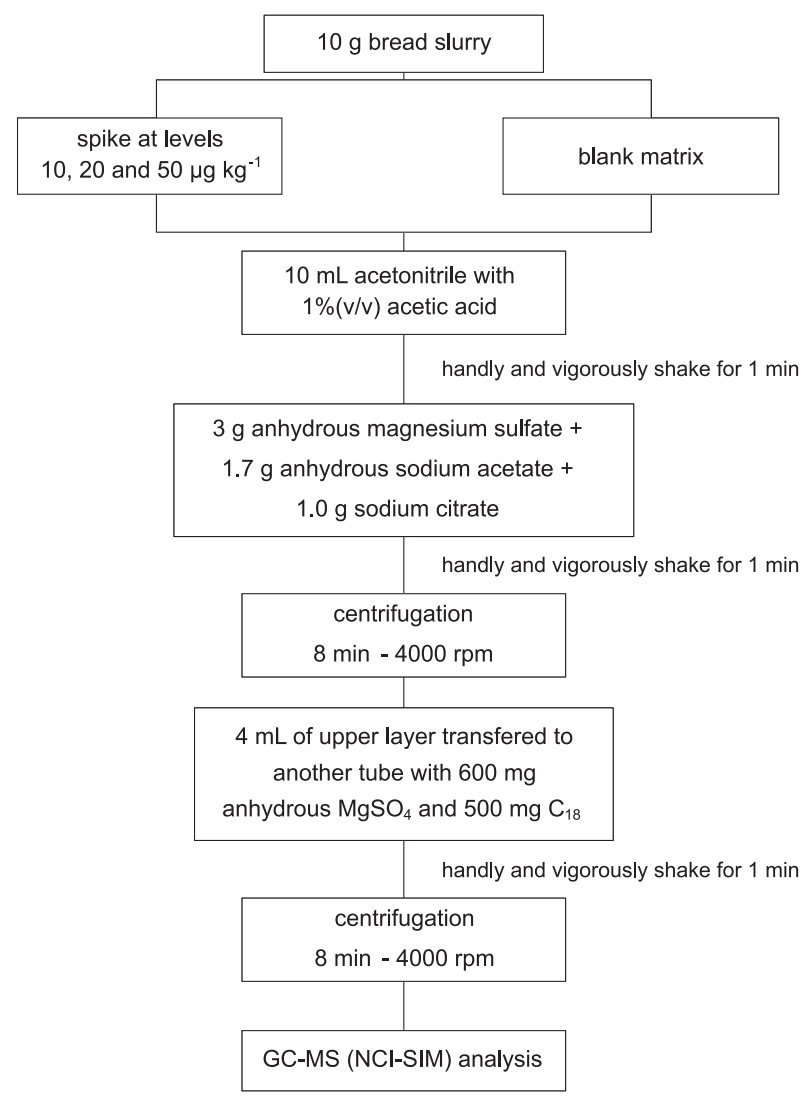

Figure 1. Scheme of the modified QuEChERS method for analysis of pesticides in bread.

(30 $\mathrm{m} \times 0.25 \mathrm{~mm}$ I.D., $0.25 \mu \mathrm{m}$ film thickness) from Varian (Middleburg, The Netherlands). Aliquots of $2 \mu \mathrm{L}$ of sample extract were injected into the gas chromatograph. The injector temperature was held at $80{ }^{\circ} \mathrm{C}$ for 0.1 min during injection and then programmed at $200{ }^{\circ} \mathrm{C} \mathrm{min}^{-1}$ to $300{ }^{\circ} \mathrm{C}$ which was held for $13 \mathrm{~min}$. The injector liner (3.4 mm i.d.) was filled with a Carbofrit plug (Restek, Bellefonte, USA). The GC oven temperature program was $80^{\circ} \mathrm{C}$ for $1.0 \mathrm{~min}$, followed by a $25^{\circ} \mathrm{C} \mathrm{min}{ }^{-1}$ ramp to $180{ }^{\circ} \mathrm{C}$ and a final ramp of $5{ }^{\circ} \mathrm{C} \mathrm{min}{ }^{-1}$ to $280{ }^{\circ} \mathrm{C}$ (held for $5 \mathrm{~min}$ ). Carrier gas was helium (99.9999\% purity; Air Products, Allentown, USA) at a constant flow-rate of $1.3 \mathrm{~mL} \mathrm{~min}^{-1}$.

The mass spectrometer was operated in negative chemical ionization (NCI) mode using methane $(99.999 \%$ purity; AGA, São Paulo, Brazil) as the reagent gas. The MS was calibrated with perfluorotributylamine (PFTBA). The MS system temperatures of the detector interface was set at $250{ }^{\circ} \mathrm{C}$, the source of ionization at $235^{\circ} \mathrm{C}$ and the manifold at $40{ }^{\circ} \mathrm{C}$. A delay time of 7.0 min was set to prevent instrument damage. The MS system was set in selective ion monitoring (SIM) mode and each compound was quantified based on peak area using three qualifier ions (Table 1). The identification and confirmation of the pesticides were performed as recommended by the European SANCO Guidelines. ${ }^{21}$

\section{Results and Discussion}

\section{Method performance and validation}

For the validation of the modified QuEChERS method we selected 15 multiclass (organochlorine, organophophorus, pyretroids and others) pesticides (Table 1) for the GC-MS (NCI-SIM) analysis, based on their relevance in wheat cultivation and storing conditions.

Table 1. Retention time and MS determination conditions

\begin{tabular}{|c|c|c|c|c|c|}
\hline No. & Pesticides & $\mathrm{t}_{\mathrm{R}} / \min$ & Monitored ions $/ \mathrm{m} / \mathrm{z}$ & Segment & time window / $\min$ \\
\hline 1 & Lindane & 8.54 & $71+73+255+253$ & 2 & $7.0-9.1$ \\
\hline 2 & Chlorothalonil & 8.89 & $266+264+268$ & 2 & \\
\hline 3 & Chlorpyrifos-methyl & 9.78 & $141+214+212$ & 3 & $9.1-10.9$ \\
\hline 4 & Pirimiphos-methyl & 10.45 & $141+304+290$ & 3 & \\
\hline 5 & Fenithrothion & 10.59 & $168+141+169$ & 3 & \\
\hline 6 & Malathion & 10.77 & $157+159+172$ & 3 & \\
\hline 7 & Chlorpyrifos-ethyl & 10.98 & $169+214+212$ & 4 & $10.9-12.0$ \\
\hline 8 & Paration-ethyl & 11.22 & $154+169+155$ & 4 & \\
\hline 9 & Dicofol & 11.49 & $250+252+251$ & 4 & \\
\hline 10 & $\alpha$-Endosulfan & 13.35 & $242+240+244$ & 5 & $12.0-15.0$ \\
\hline 11 & Endrin & 14.85 & $237+239+240$ & 5 & \\
\hline 12 & $\beta$-Endosulfan & 15.21 & $99+242+240$ & 6 & $15.0-19.0$ \\
\hline 13 & Endosulfan-sulfate & 16.44 & $97+386+80+99$ & 6 & \\
\hline 14 & Tetradifon & 19.15 & $320+318+245$ & 7 & $19.0-23.0$ \\
\hline 15 & Azoxystrobin & 26.83 & $371+356+301$ & 8 & $23.0-30.0$ \\
\hline
\end{tabular}


A good resolution of all pesticides studied was achieved with the proposed chromatographic conditions, as demonstrated in Figure 2. The good stability of the GC-MS system used and the low interference noise presented by the sample extracts permitted the quantification also of compounds less sensitive like pirimiphos-methyl. Based on the pesticides retention time, the GC-MS acquisition method was divided into as many time-windows as possible in order to maximize signal for pesticides that gave low response. ${ }^{20}$ This method consisted of 8 retention timewindow segments (Table 1).

\section{Linearity study and detection and quantification limits}

The analytical curves was evaluated with a matrixmatched standard calibration in blank extracts of bread in the concentrations $1.0 ; 2.0 ; 4.0 ; 8.0 ; 20.0 ; 50.0$ and $100.0 \mu \mathrm{g} \mathrm{L}^{-1}$, where this sequence was injected six times $(n=6)$. Calculations were performed considering the average peak areas, relative standard deviations (RSD), the determination coefficients $\left(\mathrm{r}^{2}\right)$ and also linear ranges were determined for each pesticide analyzed. Most of all pesticides analysed showed $r^{2}$ values $\geq 0.99$ and linear range from 1.0 to $100 \mu \mathrm{g} \mathrm{L}^{-1}$ (Table 2).

From the calibration curves data and the repeatability (RSD\%) of the instrument at the lowest concentration level of each pesticide, the intrument limit of detection (LODi) were estimated via the formula: $\mathrm{LODi}=3 \times \mathrm{RSD} \times$ concentration.

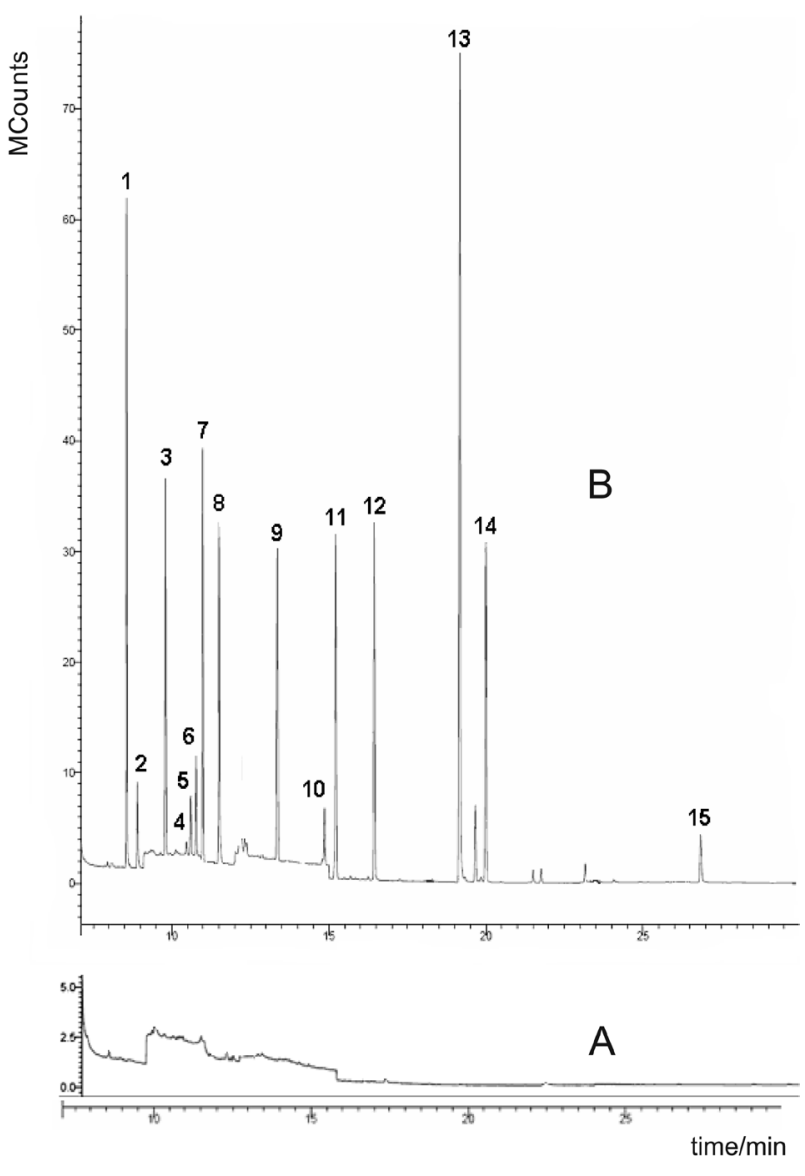

Figure 2. Total ion current chromatogram of a bread blank sample (A) and of the same sample spiked with the pesticides at $50 \mu \mathrm{g} \mathrm{kg}^{-1}(\mathrm{~B})$. Identification of the pesticides how presented in Table 1.

Table 2. Calibration data and detection and quantification limits analysed by GC-MS (NCI)

\begin{tabular}{|c|c|c|c|c|c|}
\hline Pesticicides & $\begin{array}{c}\text { Linear range / } \\
\left(\mu \mathrm{g} \mathrm{L}^{-1}\right)\end{array}$ & Calibration equation & $\mathrm{r}^{2}$ & $\begin{array}{l}\text { LODm / } \\
\left(\mu \mathrm{g} \mathrm{kg}^{-1}\right)\end{array}$ & $\begin{array}{l}\mathrm{LOQm} / \\
\left(\mu \mathrm{g} \mathrm{kg}^{-1}\right)\end{array}$ \\
\hline Lindane & $1.0-100.0$ & $y=313774 x+208982$ & 0.9981 & 3.0 & 10.0 \\
\hline Chlorothalonil & $1.0-100.0$ & $y=48953 x+5817.5$ & 0.9952 & 3.0 & 10.0 \\
\hline Chlorpyrifos-methyl & $1.0-100.0$ & $y=306375 x+35078$ & 0.9921 & 6.0 & 20.0 \\
\hline Pirimiphos-methyl & $1.0-100.0$ & $y=17958 x+26329$ & 0.9933 & 3.0 & 10.0 \\
\hline Fenithrothion & $1.0-100.0$ & $y=72329 x+42067$ & 0.9864 & 3.0 & 10.0 \\
\hline Malathion & $1.0-100.0$ & $y=84900 x+51746$ & 0.9767 & 3.0 & 10.0 \\
\hline Chlorpyrifos-ethyl & $1.0-100.0$ & $y=306375 x+35078$ & 0.9842 & 3.0 & 10.0 \\
\hline Parathion-ethyl & $1.0-100.0$ & $y=137087 x+110675$ & 0.9932 & 3.0 & 10.0 \\
\hline Dicofol & $1.0-100.0$ & $y=673192 x+211615$ & 0.9939 & 6.0 & 20.0 \\
\hline$\alpha$-Endosulfan & $1.0-100.0$ & $y=265150 x+200647$ & 0.9988 & 6.0 & 20.0 \\
\hline Endrin & $1.0-100.0$ & $y=51354 x+21601$ & 0.9901 & 3.0 & 10.0 \\
\hline$\beta$-Endosulfan & $1.0-100.0$ & $y=288112 x+306518$ & 0.9983 & 6.0 & 20.0 \\
\hline Endosulfan-sulfate & $1.0-100.0$ & $y=433838 x+486547$ & 0.9911 & 3.0 & 10.0 \\
\hline Tetradifon & $1.0-100.0$ & $y=308395 x+38078$ & 0.9985 & 6.0 & 20.0 \\
\hline Azoxystrobin & $1.0-100.0$ & $y=109167 x-23173$ & 0.9888 & 3.0 & 10.0 \\
\hline
\end{tabular}


Table 3. Recoveries \% ( $\mathrm{n}=6$ ) and RSD (\%) obtained by modified QuEChERS extraction of bread, spiked at 10, 20 and $50 \mu \mathrm{g} \mathrm{kg}^{-1}$ levels, analysed by GC-MS (NCI)

\begin{tabular}{|c|c|c|c|c|c|c|}
\hline \multirow{3}{*}{ Pesticides } & \multicolumn{6}{|c|}{ Recovery and repeatability (RSD intraday) studies spiked levels / $\left(\mu \mathrm{g} \mathrm{kg}^{-1}\right)$} \\
\hline & \multicolumn{2}{|c|}{10} & \multicolumn{2}{|c|}{20} & \multicolumn{2}{|c|}{50} \\
\hline & Rec. $(\%)$ & RSD \% & Rec. $(\%)$ & $\mathrm{RSD} \%$ & Rec. $(\%)$ & $\mathrm{RSD} \%$ \\
\hline Lindane & 76 & 6.5 & 95 & 2.0 & 93 & 2.4 \\
\hline Chlorothalonil & 78 & 6.5 & 99 & 4.3 & 122 & 7.3 \\
\hline Chlorpyrifos-methyl & 67 & 1.8 & 91 & 6.7 & 102 & 4.5 \\
\hline Pirimiphos-methyl & 63 & 8.2 & 81 & 5.1 & 90 & 5.7 \\
\hline Fenithrothion & 62 & 3.7 & 100 & 8.2 & 119 & 4.3 \\
\hline Malathion & 75 & 5.4 & 96 & 7.9 & 116 & 6.3 \\
\hline Chlorpyrifos-ethyl & 90 & 1.9 & 73 & 11.1 & 84 & 5.4 \\
\hline Parathion-ethyl & 75 & 3.9 & 90 & 3.1 & 104 & 4.8 \\
\hline Dicofol & 60 & 0.9 & 72 & 4.8 & 82 & 3.1 \\
\hline$\alpha$-Endosulfan & 66 & 1.5 & 70 & 6.0 & 75 & 1.7 \\
\hline Endrin & 68 & 9.0 & 71 & 7.4 & 85 & 2.7 \\
\hline$\beta$-Endosulfan & 66 & 8.0 & 76 & 7.3 & 83 & 3.2 \\
\hline Endosulfan-sulfate & 76 & 6.5 & 101 & 6.4 & 116 & 6.4 \\
\hline Tetradifon & 68 & 2.0 & 79 & 6.1 & 87 & 4.3 \\
\hline Azoxystrobin & 74 & 7.6 & 87 & 17.6 & 117 & 4.4 \\
\hline
\end{tabular}

This concentration should be injected and detected repeatedly for six times. The LOQi was defined as 3.3 $\times$ LODi. The real method limit of quantification (LOQm) was based on the recovery results and was defined as the lowest validated spike level meeting the requirements of 70 to $120 \%$ of recovery with $\mathrm{RSD} \leq 20 \% .{ }^{22}$ For all the analytes the LODm values were between 3.0 and $6.0 \mu \mathrm{g} \mathrm{kg}^{-1}$ and LOQm ranged from 10 to $20 \mu \mathrm{g} \mathrm{kg}^{-1}$ (Table 2).

\section{Evaluation of modified QuEChERS method}

Sample preparation, carried out following a modified QuEChERS procedure using buffered acetonitrile and clean-up with the sorbent C18 instead of primarysecondary amine (PSA), provided high throughput with adequate validation parameters and low cost per sample. The recoveries and repeatability (intraday precision) of the studied pesticides at three different spike concentration levels 10,20 and $50 \mu \mathrm{g} \mathrm{kg}^{-1}$, performed at six replicates for each level, were presented in Table 3. Mean results shown recoveries between 70 and $117 \%$ with $\mathrm{RSD} \leq 17.6 \%$. At the lowest level $\left(10 \mu \mathrm{g} \mathrm{kg}^{-1}\right)$ pesticides like azoxystrobin, chlorpyrifos-methyl, chlorothalonil, dicofol, $\alpha$-endosulfan, $\beta$-endosulfan, endrin, fenithrothion and pirimiphos-methyl not satisfied the recovery criteria for validation method, and showed recoveries between 60 and $122 \%$, but with good RSD values $(\leq 9 \%)$. The interday precision was performing during 3 consecutive days, samples spiked at 10,20 and $50 \mu \mathrm{g} \mathrm{kg}^{-1}$ levels, were analyzed. The RSD values were lower than $18.1 \%$ for all pesticides.

The developed method was applied to two commercial bread samples and residues of pirimiphos-methyl (88.2 and $\left.283.3 \mu \mathrm{g} \mathrm{kg}^{-1}\right)$ and fenithrothion $\left(26.3 \mu \mathrm{g} \mathrm{kg}^{-1}\right)$, both pesticides allowed for use in wheat grains storage.

\section{Conclusions}

In this study we optimized parameters and evaluated performance characteristics of GC-MS with negative chemical ionization for the analysis of multiple pesticides in bread. The modified QuEChERS extraction method used in this study minimized the time, labor and cost of the sample preparation. The proposed method allowed the determination at low detection limits with good precision and accuracy. The combination of quick extraction and simultaneous determination for 15 pesticides enables rapid and efficient monitoring of pesticide residues in an important food. It was confirmed that the proposed method is suitable for routine residue monitoring.

\section{Acknowledgments}

Authors gratefully acknowledge the financial support and fellowship grants from Conselho Nacional de Desenvolvimento Científico e Tecnológico (CNPq) and 
the Coordenação de Aperfeiçoamento de Pessoal de Nível Superior (CAPES), Brazil.

\section{References}

1. Pang, G. F.; Cao, Y. Z.; Zhang, J. J.; Fan, C. L.; Liu, Y. M.; Li, X. M.; Jia, G. Q.; Li, Z. Y.; Shi, Y. Q.; Wu, Y. P.; Guo, T. T.; J. Chromatogr., A 2006, 1125, 1.

2. Kihlberg, I.; Johansson, L.; Kohler, A.; Risvisk, E.; J. Cereal Sci. 2004, 39, 67.

3. Sharma, J.; Satya, S.; Kumar, V.; Tewary, D. K.; Chem. Health Safety 2005, 12, 17.

4. Kaushik, G.; Satya, S.; Kaik, S. N.; Food Res. Int. 2009, 42, 26.

5. Vela, N.; Pérez, G.; Navarro G.; Navarro, S.; J. AOAC Int. 2007, 90, 544.

6. Hercegová, A.; Dömötörová, M.; Matisová, E.; J. Chromatogr., A 2007, 1153, 54.

7. Maštovská, K.; Lehotay, S.; J. Chromatogr., A 2004, 1040, 259.

8. Lehotay, S.; Maštovská, K.; Lightfield, A. R.; J. AOAC Int. 2005, 88,615 .

9. Díez, C.; Traag, W. A.; Zommer, P.; Marinero, P.; J. Chromatogr., A 2006, 1131, 11 .

10. Aysal, P.; Ambrus, Á.; Lehotay, S. J.; Cannavan, A.; J. Environ. Sci. Health, Part B 2007, 42, 481.

11. Titato, G. M.; Bicudo, R. C.; Lanças, F. M.; Int. J. Mass Spectrom. 2007, 42, 1348.
12. Maldaner, L.; Santana, C. C.; Jardim, I. C. S. F.; J. Liq. Chromatogr. Relat. Technol. 2008, 31, 972.

13. Kolberg, D. I. S.; Presta, M. A.; Wickert, C.; Adaime, M. B.; Zanella, R.; J. Braz. Chem. Soc. 2009, 20, 1220.

14. Anastassiades, M.; Lehotay, S.; Štajnbaher, D.; Schenk, J. F.; J. AOAC Int. 2003, 86, 412.

15. Hernández-Borges, J.; Cabrera, J. C.; Rodríguez-Delgado, M. A.; Hernández-Suárez, E. M.; Saúco, V. G.; Food Chem. 2009, 113, 313 .

16. Kmellár, B.; Fodor, P.; Pareja, L.; Ferrer, C.; Martínez-Uroz, M. A.; Valverde, A.; Fernandez-Alba, A. R.; J. Chromatogr., A 2008, 1215, 37.

17. Mezcua, M.; Ferrer, C.; García-Reyes, J. F.; Martínez-Bueno, M. J.; Sigrist, M.; Fernández-Alba, A. R.; Food Chem. 2009, $112,221$.

18. Stubbings, G.; Bigwood, T.; Anal. Chim. Acta 2009, 637, 68.

19. Prestes, O. D.; Friggi, C. A.; Adaime, M. B.; Zanella, R.; Quim. Nova 2009, 32, 1620.

20. Walorczyk, S.; J. Chromatogr., A 2007, 1165, 200.

21. Walorczyk, S.; J. Chromatogr., A 2008, 1208, 202.

22. SANCO, Document no. SANCO/2007/3131; Directorate General Health and Consumer Protection, 2007, pp. 1-35.

23. Pizzutti, I.; Kok, A. de, Zanella, R.; Adaime, M. B.; Hiemstra, M.; Wickert, C.; Prestes, O. D.; J. Chromatogr. A 2007, 1142, 123.

Received: July 31, 2009 Web Release Date: March 8, 2010 